\title{
Low adherence to exercise may have influenced the proportion of OMERACT-OARSI responders in an integrated OA care model: Secondary analyses from a cluster-randomised stepped wedge trial
}

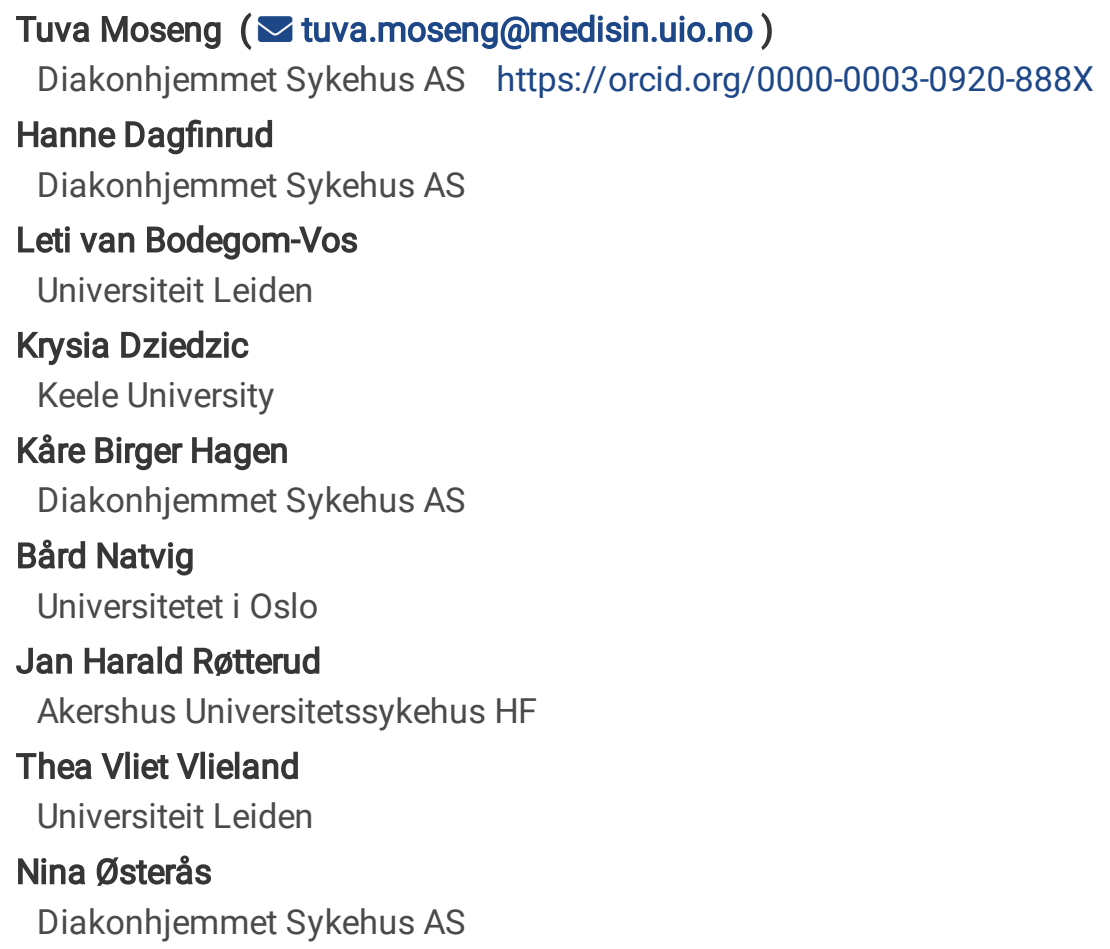

Research article

Keywords: Osteoarthritis, hip, knee, management, RCT, exercise, pain, function, responder, adherence

Posted Date: February 18th, 2020

DOI: https://doi.org/10.21203/rs.2.17081/v2

License: (c) (i) This work is licensed under a Creative Commons Attribution 4.0 International License. Read Full License 


\section{Abstract}

Background: To address the well-documented gap between hip and knee osteoarthritis (OA) treatment recommendations and current clinical practice, a structured model for integrated OA care was developed and evaluated in a stepped-wedge clusterrandomised controlled trial. The current study used secondary outcomes to evaluate clinically important response to treatment through the Outcome Measures in Rheumatology Clinical Trials clinical responder criteria (OMERACT-OARSI responder criteria) after 3 and 6 months between patients receiving the structured OA care model vs. usual care. Secondly, the study aimed to investigate if the proportion of responders in the intervention group was influenced by adherence to the exercise program inherent in the model. Methods: The study was conducted in primary healthcare in six Norwegian municipalities. General practitioners and physiotherapists received training in OA treatment recommendations and use of the structured model. The intervention group attended a physiotherapist-led OA education program and performed individually tailored exercises for 8-12 weeks. The control group received usual care. Patient-reported pain, function and global assessment of disease activity during the last week were evaluated using 11-point numeric rating scales (NRS 0-10). These scores were used to calculate the proportion of OMERACT-OARSI responders. Two-level mixed logistic regression models were fitted to investigate differences in responders between the intervention and control group. Results: 284 intervention and 109 control group participants with hip and knee OA recruited from primary care in six Norwegian municipalities. In total $47 \%$ of the intervention and $35 \%$ of the control group participants were responders at 3 or 6 months combined; showing an uncertain between-group difference (OR adjusted 1.38 (95\% $\mathrm{Cl} 0.41,4.67)$. In the intervention group, 184 participants completed the exercise programme (exercised $\geq 2$ times/week for $\geq 8$ weeks) and $55 \%$ of these were classified as responders. In contrast, $28 \%$ of the 86 non-completers were classified as responders. Conclusions: The difference in proportion of OMERACT-OARSI responders at 3 and 6 months between the intervention and control group was uncertain. In the intervention group, a larger proportion of responders were seen among the exercise completers compared to the non-completers.

\section{Background}

There is a well-documented gap between evidence and practice in the management of patients with hip and knee osteoarthritis $(1,2)$. The situation calls for development and evaluation of effective OA management programmes in order to enhance the quality of OA care and improve patient outcomes.

The international research consortium "Joint Effort Initiative" has defined an OA management program as: a model of evidencebased, non-surgical OA care implemented in a real-world clinical setting (3). Such models should, according to this definition, incorporate: i) personalised, tailored care; ii) provided as a care package with reassessments and progression; iii) incorporate at least two of the three first-line treatments (patient education, exercise and weight management); and iv) include optional evidence-based adjunctive treatments (e.g. braces, assistive devices).

We have conducted a cluster randomized controlled stepped-wedge trial to evaluate the effectiveness of implementing the structured model of integrated OA care in six Norwegian municipalities (4). The previously reported primary outcome: patientreported quality of care and associated hypotheses showed greater quality of care and satisfaction with care, more patients referred to physiotherapy and fewer to orthopedic surgeons, and more patients who fulfilled physical activity criteria in the intervention group compared to the usual care group after six months (5). Another publication from this study has further reported improved uptake of the first-line treatments in the intervention group compared to the control group, but low adherence regarding exercise adherence in the intervention group (6).

To our knowledge, only one other previous study has used a randomised controlled design (RCT) to test the effectiveness of an OA management program in primary care (7). While this study reported increased uptake of the core NICE OA recommendations, no between-group differences were found for any of the patient-reported outcomes on OA related pain and function(8). In addition, a handful of other OA management programmes, employing less rigorous, observational study designs have previously been set up in a limited number of countries $(9,10)$. Generally, these programmes report somewhat diverging, but overall promising effects on pain and physical function (11-13). In summary, more high-quality studies to evaluate effects of OA management programmes in primary care are currently warranted.

Page 2/15 
It represents a common challenge for all previous management programmes to reproduce the consistent effects on patientreported outcomes as found in the more stringent exercise RCTs, which informs the treatment recommendations $(14,15)$. As management programmes are complex, there are multitudes of possible reasons for this. In order to design programs that effectively influence OA patients' symptoms, it is vital to disentangle some of this complexity. Such investigation can identify and evaluate the importance of certain key components of a programme. One such component can be programmes' specific strategies to improve exercise adherence. High adherence is suggested to be essential to achieve the optimal symptommodifying effects from exercise for hip and knee OA (16). The direct relationship between exercise adherence and patientreported outcomes has not yet been investigated in any of the previous OA management programmes.(4)

The aim of the current secondary analyses (as predefined in the study protocol) was to explore patient-reported response to treatment between the intervention and control group including application of the Outcome Measures in Rheumatology Clinical Trials clinical responder criteria (OMERACT-OARSI responder criteria) at 3 and 6 months follow-up combined. Additionally, we aimed to further explore the intervention group by: i) Comparing the proportion of OMERACT-OARSI responders among participants completing the exercise programme (exercise for $\geq 2$ times per week for $\geq 8$ weeks) vs. the proportion among the non-completers; ii) Examine demographic and baseline patient-reported measures for associations with completing the exercise programme.

\section{Methods}

\section{Design}

The study was a cluster-randomised controlled trial, conducted with a stepped-wedge cohort design in six neighbouring Norwegian municipalities (clusters) between January 2015 and October 2017. The study involved general practitioners (GPs), physiotherapists (PTs) and patients with symptomatic hip and knee OA. In the stepped-wedge design all clusters started the trial simultaneously in control phase, before switching to intervention phase in a randomised order based on pre-defined time points. The design is explained in detail in Figure 1.

The study protocol has been published previously (4). The study is reported according to the CONSORT checklist (Additional file 2).

According to the stepped-wedge design the six municipalities (clusters) were randomly assigned to one of the six sequences for time of cross-over from control to intervention phase using a computer-generated list of random numbers provided by a statistician. To ensure a mix of municipality sizes in the randomised sequence, stratification on the number of inhabitants (less than versus more than 20,000) was performed. Due to the nature of the intervention, it was not possible to blind the involved GPs, PTs or patients.

Patient-reported outcomes were collected at baseline at 3 and 6 month's follow-up, using electronic questionnaires.

\section{Participants}

All GPs and all PTs working in private practice or in a Healthy Life Centre in the six municipalities were invited to participate in the study. Potential patients eligible for the study were identified by their GP or PT with the following inclusion criteria: age $\geq 45$ years with activity-related hip and/or knee pain/complaints and clinical signs and symptoms corresponding to hip and/or knee $\mathrm{OA}$ or radiologically diagnosed OA or registered in the medical journal with a hip or knee OA diagnosis.

Patients who did not understand the Norwegian language; had undergone joint replacement for all affected hip/knee OA joints; or had inflammatory rheumatic diseases, malignant illness or other major conditions that restricted their ability to adhere to the treatment recommendations were excluded. Patient participants included during the control phases constituted the control group, whereas patient participants included during the intervention phases constituted the intervention group.

\section{Intervention}


The SAMBA model for integrated OA care (Additional file 1, Figure A) was developed by the research team and included a structured pathway for the patient through the health care system. "SAMBA" is the acronym for the Norwegian study title, "Collaboration for improved OA care."

The model should provide the patient with access to timely recommended care.

Interactive workshops for GPs and PTs were the main activity to ensure implementation of the SAMBA model in clinical practice. The workshops were arranged separately for each municipality, in close proximity to the time for crossover from control to intervention phase. During the workshops, the PTs received education in the delivery of the standardized patienteducation programme and of the individually tailored exercise programme. The PTs received access to a database with recommended exercises and dose recommendations. The exercises were selected from the exercise programmes of the Swedish BOA and Danish GLA:D OA management programmes and previously published well-recognized, effective exercise programmes to impact hip and knee OA symptoms $(4,17,18)$.

The group-based patient education programme lasted 3 hours and was based on a standardized template (Power-Point with optional manuscript). The patient education focused on providing the patient with knowledge of OA and recommend treatments, emphasizing the importance of exercise.

Following individual patient examinations, the PTs prescribed individually tailored exercise programmes with the main aim to improve muscular strength, in order to reduce OA symptoms. The PTs were instructed to closely monitor the individual patients' performance and to regularly adjust exercise dose and degree of difficulty to facilitate progression. Dose recommendations were based on acknowledged, international guidelines from American College of Sports Medicine (ACSM), and included gradually increasing the dose towards 2-4 sets with 8-12 repetitions of $60 \%-70 \%$ of 1 repetition maximum or more if tolerated (19). The PTs were instructed to increase the resistance when the patient could perform 2 extra repetitions in the last set ("The $2+$ principle").

The patients performed their individual exercise programmes in groups of 5-10 patients per PT. The exercise period lasted $8-12$ weeks, with two supervised weekly sessions. The patients were encouraged to add a third home-based session consisting of 3060 min cardiorespiratory exercise like brisk walking, running or bicycling. Patients who did not wish to attend the group sessions had the option of performing their exercise individually, but were expected to consult their PT for regular adjustments of the programme.

During the control phase, the GPs and PTs provided usual care for their OA patients. Usual care can be heterogeneous in nature and could include any treatment the GP and patient considered appropriate. Physiotherapy (all kind of modalities) was allowed, but not provided by a PT who had participated in the workshops.

\section{Outcome measures}

Patient-reported outcomes were evaluated at 3 and 6 months. These included pain, physical function, stiffness and patient global assessment of disease activity during the last week evaluated using 11-point Numeric Rating Scales (NRS) ( $0=$ best, $10=$ worst). Hip/knee related quality of life was evaluated with the Hip disability and Osteoarthritis Outcome Score (HOOS) and Knee injury and Osteoarthritis Outcome Score (KOOS), quality of life subscale, (0-100, 100=no problems). Daily hours spent in sitting position was evaluated with one question asking: "how many hours do you usually spend in sitting position during a regular day". The scores from the pain, function and patient global assessment of disease activity outcomes were used to calculate the proportion of OMERACT-OARSI responders (20) (in the two groups) at 3 and 6 months. A participant was classified as a responder if one of the following were fulfilled:

1) High improvement in pain or function

- $\geq 50 \%$ improvement + absolute change of $\geq 2$ in pain, OR

- $\geq 50 \%$ improvement + absolute change of $\geq 2$ in function 
2) Improvement in at least two of the three following:

- $\geq 20 \%$ improvement + absolute change $\geq 1$ in pain

- $\geq 20 \%$ improvement + absolute change $\geq 1$ in function

- $\geq 20 \%$ improvement + absolute change $\geq 1$ in the patient global assessment of disease activity

A participant was characterized as having completed the exercise programme if having exercised for $\geq 2$ times per week for $\geq 8$ weeks. The information on the number of completed exercise sessions was derived from participants' exercise diaries and attendance lists from the PTs if exercise diaries were not returned or incomplete.

\section{Statistical analysis}

Sample size calculations were not conducted for secondary outcomes of the study. For the main outcome, it was calculated a need for a total of 388 participants (4).

Descriptive analyses were conducted for baseline, 3 and 6 months characteristics.

The difference in pain, function, disease activity and proportion of OMERACT-OARSI responders between the intervention and control group were investigated using two-level mixed regression models with random effects for cluster and individual participant and fixed effects for age, gender, BMI and time trends (month of inclusion) on an intention to treat basis. The linear models for pain, function and disease activity included an interaction term of follow-up time point and group. The difference in OMERACT-OARSI responders at 3 and 6 months was investigated using a logistic model. The proportion of responders was investigated separately for 3 and 6 months and for these time-points combined. These models account for missing under a missing at random assumption.

In the intervention group, the difference in the proportion of responders between the participants completing the exercise programme (exercise for $\geq 2$ times per week for $\geq 8$ weeks) and the non-completers were compared using descriptive statistics.

To investigate potential associations between completing the exercise programme and baseline characteristics a two-level mixed logistic regression was fitted. The model included random effects for cluster and individual participant. The set of baseline characteristics (fixed effects) were selected based on experience and previous literature of variables suggested to have an impact on exercise adherence using a fit full model approach. The selected variables were age, gender, BMI, , education ( $<1$ / $\geq 1$ year of university), employment (yes/no), cohabitation (yes/no), multisite OA (yes/no), pain last week (NRS 0-10) and selfefficacy (Arthritis Self-Efficacy Scale (ASES) mean score of Pain and Function subscales (10-100, "very uncertain" to "certain") (21). The model was additionally adjusted for time trends (month of inclusion), investigated for possible multicollinearity and the goodness of fit using Hosmer and Lemeshow test.

The significance level for the analyses was set at $p<0.05$.

\section{Patient and public involvement}

Two patient research partners were members of the trial steering group and involved in all stages of this trial including grant application, development of study material (patient information, consent procedures, questionnaires), intervention, interpretation and dissemination of the results.

\section{Results}

A total of 393 patients with hip and/or knee OA were included, 109 during the control phases (=control group) and 284 during the intervention phases (=intervention group). Figure 1 illustrates the flow of participants through the study and provides reasons for ineligibility or exclusion. Baseline characteristics of the participants are displayed in Table 1. 
Table 1. Baseline characteristics of patients with osteoarthritis participating in the SAMBA study

\begin{tabular}{|c|c|c|c|}
\hline & $\begin{array}{l}\text { All participants } \\
(\mathrm{n}=393)\end{array}$ & $\begin{array}{l}\text { Intervention group } \\
(\mathrm{n}=284)\end{array}$ & $\begin{array}{l}\text { Control group } \\
(\mathrm{n}=109)\end{array}$ \\
\hline Age, mean (SD) & $63(10)$ & $63(10)$ & $65(10)$ \\
\hline Sex, female, n (\%) & $280(71)$ & $211(74)$ & $68(62)$ \\
\hline BMI, mean (SD) & $29(6)$ & $29(6)$ & $28(5)$ \\
\hline \multicolumn{4}{|l|}{ Education } \\
\hline$\geq 1$ year university, $\mathrm{n}(\%)$ & $136(35)$ & $101(36)$ & $35(32)$ \\
\hline \multicolumn{4}{|l|}{ Main affected joint, n (\%) } \\
\hline Knee & $228(58)$ & $174(61)$ & $54(49)$ \\
\hline Hip & $146(37)$ & $100(35)$ & $46(42)$ \\
\hline Other* & $18(6)$ & $9(3)$ & $9(8)$ \\
\hline Multi-site OA, n (\%)** & $339(86)$ & $244(86)$ & $95(87)$ \\
\hline
\end{tabular}

In total $88 \%(n=348)$ completed the patient-reported questionnaires at 3 months, and $88 \%(n=345)$ at 6 months follow-up (Figure 1). Those not responding to the symptom-related questions at 3 or 6 months were similar to those responding with regard to baseline characteristics. Seven (6\%) OA patients in the control group and $3(1 \%)$ in the intervention group received joint replacement surgery between baseline and the 6-month follow-up..

In the intervention group, $65 \%(n=184)$ exercised $\geq 2$ times per week for $\geq 8$ weeks. Four patients in the intervention group experienced increased prolonged knee pain and/or swelling and discontinued the exercise programme at the halfway stage. Of the 102 included control group participants, $43 \%$ self-reported having received physiotherapy once or more between baseline and 6 months.

\section{Pain, function, disease activity and OMERACT-OARSI responders}

The mean differences in the patient-reported outcomes and proportion of OMERACT-OARSI responders at 3 and 6 months are presented in Table 2. At both 3 and 6 months the intervention group reported marginally less pain, disease activity, and improved function compared to the control group on the 0-10 scale. Similar results were also seen for $\mathrm{H} / \mathrm{KOOS}$ quality of life subscale, with marginally higher scores in the intervention group and slightly less time spent in sitting position at 3 and 6 months. 
le 2. Differences in patient-reported outcomes and OMERACT-OARSI responders between the intervention and control group at 3 and 6 months iw-up

\begin{tabular}{|c|c|c|c|c|c|c|c|c|c|c|c|c|c|c|}
\hline & $\begin{array}{l}B L \\
n=283\end{array}$ & $\begin{array}{l}3 \text { mos. } \\
\mathrm{n}=242\end{array}$ & $\begin{array}{l}6 \text { mos. } \\
n=239\end{array}$ & $\begin{array}{l}3+6 \\
\text { mos. }\end{array}$ & $\begin{array}{l}\mathrm{BL} \\
\mathrm{n}=109\end{array}$ & $\begin{array}{l}3 \text { mos. } \\
n=106\end{array}$ & $\begin{array}{l}6 \text { mos. } \\
\mathrm{n}=106\end{array}$ & $\begin{array}{l}3+6 \\
\text { mos. }\end{array}$ & $\begin{array}{l}\text { Control vs. } \\
\text { intervention } \\
3 \text { mos. (95 } \\
\% \text { CI) }\end{array}$ & $p$ & $\begin{array}{l}\text { Control vs. } \\
\text { intervention } \\
6 \text { mos. (95 } \\
\% \text { CI) }\end{array}$ & $p$ & $\begin{array}{l}\text { Control vs. } \\
\text { Intervention } \\
\text { group 3+6 } \\
\text { mos. (95\% } \\
\text { CI) }\end{array}$ & $p$ \\
\hline $\begin{array}{r}\text { Pain last } \\
\text { ek (NRS } \\
0-10) \\
\text { san (SD) }\end{array}$ & $\begin{array}{r}5.4 \\
(2.0)\end{array}$ & $\begin{array}{l}4.4 \\
(2.0)\end{array}$ & $\begin{array}{l}4.2 \\
(2.1)\end{array}$ & & $\begin{array}{r}5.1 \\
(1.8)\end{array}$ & $\begin{array}{c}4.7 \\
(2.2)\end{array}$ & $\begin{array}{c}4.7 \\
(2.1)\end{array}$ & & $\begin{array}{r}\text { b: }-0.65 \\
(-1.26 \\
0.04)\end{array}$ & 0.04 & $\begin{array}{r}\text { b: }-0.98 \\
(-1.59 \\
-0.37)\end{array}$ & 0.002 & & \\
\hline $\begin{array}{l}\text { "unction } \\
\text { ast week } \\
\text { (NRS 0- } \\
\text { )), mean } \\
\text { (SD) }\end{array}$ & $\begin{array}{r}5.2 \\
(2.0)\end{array}$ & $\begin{array}{c}4.4 \\
(1.9)\end{array}$ & $\begin{array}{c}4.1 \\
(2.1)\end{array}$ & & $\begin{array}{r}4.9 \\
(1.9)\end{array}$ & $\begin{array}{r}4.6 \\
(2.3)\end{array}$ & $\begin{array}{c}4.7 \\
(2.1)\end{array}$ & & $\begin{array}{r}b:-0.67 \\
(-1.28 \\
0.06)\end{array}$ & 0.03 & $\begin{array}{r}b:-1.17 \\
(-1.78, \\
-0.56)\end{array}$ & $<0.001$ & & \\
\hline $\begin{array}{r}\text { Disease } \\
\text { vity last } \\
\text { ek (NRS } \\
0-10) \\
\text { tan (SD) }\end{array}$ & $\begin{array}{r}5.3 \\
(2.0)\end{array}$ & $\begin{array}{r}4.3 \\
(2.0)\end{array}$ & $\begin{array}{r}4.2 \\
(2.1)\end{array}$ & & $\begin{array}{r}4.8 \\
(2.0)\end{array}$ & $\begin{array}{r}4.7 \\
(2.3)\end{array}$ & $\begin{array}{c}4.7 \\
(2.2)\end{array}$ & & $\begin{array}{r}\text { b: }-0.93 \\
(-1.55 \\
-0.31)\end{array}$ & 0.003 & $\begin{array}{r}\text { b: }-1.02 \\
(-1.64 \\
-0.39)\end{array}$ & 0.001 & & \\
\hline $\begin{array}{r}\text { [ERACT- } \\
\text { OARSI } \\
\text { sonders, } \\
n(\%)\end{array}$ & & $\begin{array}{r}92 \\
(33)\end{array}$ & $\begin{array}{r}99 \\
(35)\end{array}$ & $\begin{array}{l}132 \\
(47)\end{array}$ & & $\begin{array}{r}24 \\
(23)\end{array}$ & $\begin{array}{r}24 \\
(23)\end{array}$ & $\begin{array}{r}36 \\
(35)\end{array}$ & $\begin{array}{c}\text { OR: } 1.37 \\
(0.26,7.24)\end{array}$ & 0.7 & $\begin{array}{r}\text { OR: } 2.81 \\
(0.32, \\
24.67)\end{array}$ & 0.3 & $\begin{array}{r}\text { OR: } 1.38 \\
(0.41,4.67)\end{array}$ & 0.6 \\
\hline $\begin{array}{r}\text { Stiffness } \\
\text { ast week } \\
(\text { NRS 0- } \\
\text { )), mean } \\
\text { (SD) }\end{array}$ & $\begin{array}{r}5.3 \\
(2.3)\end{array}$ & $\begin{array}{r}4.5 \\
(2.1)\end{array}$ & $\begin{array}{r}4.3 \\
(2.1)\end{array}$ & & $\begin{array}{r}4.9 \\
(2.2)\end{array}$ & $\begin{array}{r}4.6 \\
(2.1)\end{array}$ & $\begin{array}{r}4.9 \\
(2.1)\end{array}$ & & $\begin{array}{c}\text { b: }-0.63 \\
(-1.28 \\
0.01)\end{array}$ & 0.05 & $\begin{array}{c}\text { b: }-1.10 \\
(-1.74 \\
-0.45)\end{array}$ & 0.001 & & \\
\hline $\begin{array}{r}\mathrm{H} / \mathrm{KOOS} \\
\text { QoL } \\
\text { subscale } \\
\text { san (SD) }\end{array}$ & $\begin{array}{r}44.9 \\
(16.3)\end{array}$ & $\begin{array}{r}47.8 \\
(14.9)\end{array}$ & $\begin{array}{r}49.7 \\
(15.8)\end{array}$ & & $\begin{array}{r}49.9 \\
(17.2)\end{array}$ & $\begin{array}{r}45.3 \\
(18.2)\end{array}$ & $\begin{array}{r}47.2 \\
(17.5)\end{array}$ & & $\begin{array}{r}\text { b: } 5.43 \\
(0.59 \\
10.27)\end{array}$ & 0.03 & $\begin{array}{c}\text { b: } 5.11 \\
(0.28,9.95)\end{array}$ & 0.04 & & \\
\hline $\begin{array}{l}\text { ly hours } \\
\text { n sitting } \\
\text { गosition, } \\
\text { san (SD) }\end{array}$ & $\begin{array}{r}6.5 \\
(2.8)\end{array}$ & $\begin{array}{r}6.1 \\
(2.8)\end{array}$ & $\begin{array}{r}5.9 \\
(2.6)\end{array}$ & & $\begin{array}{r}6.8 \\
(3.6)\end{array}$ & $\begin{array}{c}6.4 \\
(3.2)\end{array}$ & $\begin{array}{r}6.2 \\
(3.0)\end{array}$ & & $\begin{array}{r}\text { b:-1.17 } \\
\text { (-2.04, } \\
-0.31)\end{array}$ & 0.008 & $\begin{array}{r}b:-1.47 \\
(-2.33 \\
-0.60)\end{array}$ & 0.001 & & \\
\hline
\end{tabular}

ieta. OR= Odds Ratio. Estimates are adjusted for patient age, sex, BMI and study months (number of months between study initiation and the ents' baseline questionnaire). H/KOOS QoL = Hip disability and Osteoarthritis Outcome Score/ Knee injury and Osteoarthritis Outcome Score, lity of Life subscale, $(0-100.100=$ no problems).

When applying the follow-up data to the OMERACT-OARSI responder criteria the proportion of responders at 3 months was $33 \%$ $(n=92)$ in the intervention group compared to $23 \%(n=24)$ in the control group. At 6 months we found $35 \%(n=99)$ responders in the intervention group compared to $23 \%(n=24)$ responders in the control group. When the total number of responders at 3 and 6 months was combined $47 \%(n=132)$ in the intervention group and $35 \%(n=36)$ in the control group were classified as responders.

\section{OMERACT-OARSI responders and adherence to the exercise programme (intervention group)}

Of the 184 intervention group patients who completed the exercise programme $55 \%(n=101)$ were classified as OMERACTOARSI responders at 3 or 6 months combined. For the 86 patients who did not complete the exercise programme, 28\% ( $n=24)$ were classified as OMERACT-OARSI responders at 3 or 6 months combined. Data were missing from 14 participants.

Differences in pain, physical function and disease activity between the exercise programme completers and non-completers at baseline and 3 and 6 months follow-up are displayed in Figure 2. The figure indicates that the participants completing the 
exercise programme report more baseline symptoms, but also have a more beneficial symptom trajectory from baseline to 3 and 6 months compared to the non-completers.

\section{Factors associated with completing the exercise programme (intervention group)}

Results of the logistic regression analysis to explore measures associated with completing the exercise programme are displayed in Table 3. The variables multisite $\mathrm{OA}$ and employment were removed from the model due to multicollinearity. In this model none of the selected variables was significantly associated with completing the exercise programme.

Table 3. Association between exercise programme completers and selected baseline variables

\begin{tabular}{|c|c|c|c|c|}
\hline \multirow[b]{2}{*}{ Variable } & \multirow[b]{2}{*}{ Completern $=184$} & \multicolumn{2}{|c|}{ Non-Completer** } & \multirow[b]{2}{*}{$p$} \\
\hline & & $\mathrm{n}=86$ & Adjusted OR $(95 \% \mathrm{CI})^{* * *}$ & \\
\hline Age, mean (SD) & $63.4(9.5)$ & $61.3(9.8)$ & $1.02(0.98,1.05)$ & 0.2 \\
\hline Sex, female, n (\%) & $141(77.0)$ & $62(72.1)$ & $1.60(0.86,3.00)$ & 0.1 \\
\hline BMI, mean (SD) & $28.5(5.5)$ & $29.8(5.9)$ & $0.97(0.92,1.02)$ & 0.2 \\
\hline Education, $\geq 1$ year university, $\mathrm{n}(\%)$ & $65(35.7)$ & $28(32.9)$ & $1.07(0.60,1.91)$ & 0.8 \\
\hline Living with someone, $\mathrm{n}(\%)$ & $144(78.7)$ & $66(77.6)$ & $1.25(0.63,2.45)$ & 0.5 \\
\hline Self-efficacy (10 worst-100 best), mean (SD) & $57.9(17.6)$ & $55.5(21.1)$ & $1.01(0.99,1.02)$ & 0.4 \\
\hline Pain (NRS 0-10), mean (SD) & $5.2(1.9)$ & $5.7(2.1)$ & $0.94(0.80,1.09)$ & 0.4 \\
\hline
\end{tabular}

The model includes random effects of cluster and individual participant and fixed effects for the other included variables and with additional adjustments for time (month of inclusion). OR=Odds ratio

\section{Discussion}

Only small differences in mean pain, function, stiffness, disease activity, hip/knee related quality of life and hours spent sitting were observed between the intervention and control group at 3 and 6 months follow-up. The estimated difference in the proportion of participants fulfilling the OMERACT-OARSI responder criteria between the intervention and control group at 3 and 6 months combined was uncertain. A larger proportion of the intervention group participants who completed the exercise fulfilled the OMERACT-OARSI responder criteria compared to the non-completers. No demographic or baseline patient-reported measures were significantly associated with completing the exercise programme among the intervention group participants. The results indicate differences in the trajectories of pain, physical function and disease activity between exercise programme completers and non-completers.

These results display some of the challenges and complexities of implementing OA treatment recommendations in real-world clinical practice. In this study, we have targeted the structure of care delivery, educated health professionals and provided readily available tools to ease the delivery of recommended treatment alternatives (4). Unfortunately, this intervention was not sufficient to show a clinically meaningful difference in patient-reported outcomes and a statistically significant difference in proportion of OMERACT-OARSI responders in the intervention group compared to the usual care control group. However, the total proportion of responder in the intervention group ( $47 \%$ ) is similar to previous RCTs applying the OMERACT-OARSI responder criteria to evaluate the effect of different physiotherapist led exercise interventions on knee OA (22-24).

As much as $43 \%$ of the control group participants reported receiving at least one session of physiotherapy between baseline and 6 months. This could have influenced the relative high proportion of responders in the control group (35\%) and thus contributed to the non-significant difference in proportion of responders between the intervention and control group.

When investigating the intervention group further, the proportion of responders was higher among the participants completing the exercise programme ( $55 \%$ ) compared to the non-completers ( $28 \%$ ). We believe this result highlights that adherence to exercise is an important component which needs to be thoroughly addressed to achieve the best possible results on pain and physical function in OA management programmes $(25,26)$. In contrast, a recent study investigating adherence to a home- 
exercise programme for patients with knee OA was unable to show any relationship between exercise adherence and pain and self-reported function (27). Yet, the authors were only able to use exercise frequency as a measure of adherence, which is the similar measure we have applied in the current analyses. In a separate paper reporting from the SAMBA study, we showed that a large proportion of the patients who exercised according to recommended frequency did not follow the recommendations for intensity, nor received the recommended progression in their exercise programmes (28). We do, however recognize the weakness of this comparison as we have only used descriptive statistics. Outcomes such as psychological factors and comorbidities might be confounding factors in the relationship between responders and exercise adherence (29). However, we decided not to perform advanced statistics on subset of data from the current RCT, due to the a high risk of bias associated with such analyses (30). Two recent systematic reviews have given evidence that not only exercise frequency but also exercise intensity is important to impact OA symptoms in hip and knee OA (31-33). The combination of these findings suggests that the proportion of responders in the intervention group could have been higher if more participants followed the ACSM recommendations on both exercise frequency and intensity (19). However, improved adherence to exercise in clinical practice is not easily achieved. Previous studies have found small effects of certain behaviour change techniques and booster sessions to improve exercise adherence among patients $(34,35)$. How to effectively improve exercise adherence in patients with hip and knee OA is a current research priority (36), which should be further studied also within the current setting. Patient motivation and beliefs may be important factors to consider (37).

None of the demographic or baseline patient-reported measures were significantly associated with completing the exercise programme among the intervention group participants. A previous study has pointed to low-income and no baseline pain with pivoting and twisting as predictors for non-adherence to exercise in patients with meniscal tears and knee osteoarthritis (38). Our data also indicates that participants not completing the exercise programme have a lower symptom burden at baseline compared to the completers. It is however, unknown if the participants completing the exercise program had a better response due to the higher symptom burden at baseline or due to completing the exercise program. For future studies it is relevant to examine this relationship further.

\section{Strengths and limitations}

A major strength of this study is the randomised controlled design, combined with the broad inclusion criteria and pragmatic set-up. This combination provides a high external validity of the results toward real-life clinical practice. The usual care control group made it possible to form valid conclusions of the effectiveness of the SAMBA model regarding difference in proportion of responders between the intervention and control group. Another strength was the application of the OMERACT-OARSI responder criteria which is a recommended tool to assess change in OA symptoms after non-pharmacological interventions both in research and clinical practice (39).

Our study also holds some limitations which should be considered. Firstly, the analyses were conducted from secondary outcomes of an RCT. Power calculations were not performed for these outcomes. Secondly, our measure of adherence was a mix between data from patients' self-reported exercise diaries and the physiotherapists' attendance lists. It is known that people tend to overestimate exercise behaviour (40). On the other hand, it is also possible that participants would sometimes forget to record their exercise sessions. Patients could also have exercised at home, which the PTs would not be able to document on their attendance lists. It is therefore a risk that exercise adherence could be both over- and underestimated. Due to this limitation we chose not to conduct a more sophisticated statistical analysis on the influence of exercise adherence on the proportion of responders. Methods such as a complier average causal effect analysis could have been appropriate if such methods had been developed for cluster-randomized stepped-wedge trials. Thirdly, the size of the groups is unbalanced due to a higher recruitment rate during the intervention phases of the study. As potential patient participants were identified by their GP and $\mathrm{PT}$, it is possible that a recruitment bias exists.

\section{Conclusions}

To conclude, we found an uncertain difference between the proportion of OMERACT-OARSI responders in the intervention and control group at 3 and 6 months combined. In the intervention group, the proportion of responders was higher among the 
completers of the exercise programme vs. the non-completers. None of the selected demographic or patient-reported baseline variables was associated with completing the exercise programme among the intervention group participants. Hence, exercise adherence may be an important contributing factor to achieve patient-reported effects within OA care models in primary care.

\section{List Of Abbreviations}

OA: Osteoarthritis; NRS: Numeric Rating Scale; OR: Odds Ratio; Cl: Confidence Interval; RCT: Randomized Controlled Trial; GP: General Practitioner; PT: Physiotherapist; ACSM: American College of Sports Medicine; ASES: Arthritis Self-Efficacy Scale; MD: Mean Difference

\section{Declarations}

\section{Ethics approval and consent to participate}

The Regional Committee for Medical and Health Research Ethics in Norway, appointed by the Ministry of Education and Research issued a letter of exempt for the current study (Ref. No: 2014/1739 REK south-east C). The Norwegian Data Inspectorate/ Data Protection Official approved the study on December $22^{\text {nd }} 2014$. The study was conducted in accordance with the principles of the Helsinki declaration. All participants gave written informed consent before data collection began.

\section{Consent for publication}

Not applicable

\section{Availability of data and materials}

The datasets generated and analysed during the current study are not publicly available due to privacy regulations but are available from the corresponding author on reasonable request.

\section{Competing interests}

Professor Dziedzic was part-funded by the National Institute for Health Research (NIHR) Collaborations for Leadership in Applied Health Research and Care West Midlands and a Knowledge Mobilisation Research Fellowship (KMRF- 2014-03-002) from the NIHR, and is an NIHR Senior Investigator.

\section{Funding}

The study was funded by the Norwegian Fund for Postgraduate Training in Physiotherapy (grant ID 62458) and The Research Council of Norway (no: 229079).

\section{Authors' contributions}

$\mathrm{N} \varnothing, \mathrm{TM}, \mathrm{HD}$ and $\mathrm{KBH}$ cooperated in the conception and design of the study. $\mathrm{N} \varnothing$ and $\mathrm{TM}$ were responsible for managing the study and acquisition of all data. NØ, TM and HD conducted the analyses and interpreted the data. TM was responsible for drafting the manuscript. TM, HD, LBV, KD, KBH, BN, JHR, TVV and Nø revised the manuscript critically for important intellectual content. All authors approved the final version of the manuscript.

\section{Acknowledgements}

The authors would like to acknowledge The Norwegian Fund for Post-Graduate Training in Physiotherapy and The Research Council of Norway for funding the study.

\section{References}


1. Basedow M, Esterman A. Assessing appropriateness of osteoarthritis care using quality indicators: a systematic review. Journal of evaluation in clinical practice. 2015;21(5):782-9.

2. Hagen KB, Smedslund G, Osteras N, Jamtvedt G. Quality of Community-Based Osteoarthritis Care: A Systematic Review and Meta-Analysis. Arthritis care \& research. 2016;68(10):1443-52.

3. Eyles JP, Hunter DJ, Bennell KL, Dziedzic KS, Hinman RS, van der Esch M, et al. Priorities for the effective implementation of osteoarthritis management programs: an OARSI international consensus exercise. Osteoarthritis and cartilage / OARS, Osteoarthritis Research Society. 2019;27(9):1270-9.

4. Osteras N, van Bodegom-Vos L, Dziedzic K, Moseng T, Aas E, Andreassen O, et al. Implementing international osteoarthritis treatment guidelines in primary health care: study protocol for the SAMBA stepped wedge cluster randomized controlled trial. Implementation science : IS. 2015;10:165.

5. Østerås N, Moseng T, Bodegom-Vos LV, Dziedzic K, Mdala I, Natvig B, et al. Implementing a structured model for osteoarthritis care in primary healthcare: A stepped-wedge cluster-randomised trial. PLOS Medicine. 2019;16(10):e1002949.

6. Moseng T, Dagfinrud H, Osteras N. Implementing international osteoarthritis guidelines in primary care: uptake and fidelity among health professionals and patients. Osteoarthritis and cartilage / OARS, Osteoarthritis Research Society. 2019;27(8):1138-47.

7. Dziedzic KS, Healey EL, Porcheret M, Afolabi EK, Lewis M, Morden A, et al. Implementing core NICE guidelines for osteoarthritis in primary care with a model consultation (MOSAICS): a cluster randomised controlled trial. Osteoarthritis and cartilage / OARS, Osteoarthritis Research Society. 2018;26(1):43-53.

8. National Institute for Health \& CareExcellence (NICE). Osteoarthritis: Care and management in adults. Clinical guideline (CG177). London: NICE; 2014.

9. Smink AJ, van den Ende CH, Vliet Vlieland TP, Swierstra BA, Kortland JH, Bijlsma JW, et al. "Beating osteoARThritis": development of a stepped care strategy to optimize utilization and timing of non-surgical treatment modalities for patients with hip or knee osteoarthritis. Clinical rheumatology. 2011;30(12):1623-9.

10. Allen KD, Choong PF, Davis AM, Dowsey MM, Dziedzic KS, Emery C, et al. Osteoarthritis: Models for appropriate care across the disease continuum. Best practice \& research Clinical rheumatology. 2016;30(3):503-35.

11. Smink AJ, van den Ende CH, Vliet Vlieland TP, Bijlsma JW, Swierstra BA, Kortland JH, et al. Effect of stepped care on health outcomes in patients with osteoarthritis: an observational study in Dutch general practice. The British journal of general practice : the journal of the Royal College of General Practitioners. 2014;64(626):e538-44.

12. Jönsson T, Ekvall Hansson E, Thorstensson CA, Eek F, Bergman P, Dahlberg LE. The effect of education and supervised exercise on physical activity, pain, quality of life and self-efficacy - an intervention study with a reference group. BMC musculoskeletal disorders. 2018;19(1):198.

13. Skou ST, Roos EM. Good Life with osteoArthritis in Denmark (GLA:D): evidence-based education and supervised neuromuscular exercise delivered by certified physiotherapists nationwide. BMC musculoskeletal disorders. 2017;18(1):72.

14. Fransen M, McConnell S, Harmer AR, Van der Esch M, Simic M, Bennell KL. Exercise for osteoarthritis of the knee. The Cochrane database of systematic reviews. 2015;1:Cd004376.

15. Fransen M, McConnell S, Hernandez-Molina G, Reichenbach S. Exercise for osteoarthritis of the hip. The Cochrane database of systematic reviews. 2014;4:Cd007912.

16. Roddy E, Zhang W, Doherty M, Arden NK, Barlow J, Birrell F, et al. Evidence-based recommendations for the role of exercise in the management of osteoarthritis of the hip or knee-the MOVE consensus. Rheumatology(Oxford). 2005;44(1):67-73.

17. Stensrud S, Roos EM, Risberg MA. A 12-week exercise therapy program in middle-aged patients with degenerative meniscus tears: a case series with 1-year follow-up. The Journal of orthopaedic and sports physical therapy. 2012;42(11):919-31.

18. Fernandes L, Storheim K, Nordsletten L, Risberg MA. Development of a therapeutic exercise program for patients with osteoarthritis of the hip. Physical therapy. 2010;90(4):592-601.

19. Garber CE, Blissmer B, Deschenes MR, Franklin BA, Lamonte MJ, Lee IM, et al. American College of Sports Medicine position stand. Quantity and quality of exercise for developing and maintaining cardiorespiratory, musculoskeletal, and 
neuromotor fitness in apparently healthy adults: guidance for prescribing exercise. MedSciSports Exerc. 2011;43(7):133459.

20. Pham T, van der Heijde D, Altman RD, Anderson JJ, Bellamy N, Hochberg M, et al. OMERACT-OARSI initiative: Osteoarthritis Research Society International set of responder criteria for osteoarthritis clinical trials revisited. Osteoarthritis and cartilage / OARS, Osteoarthritis Research Society. 2004;12(5):389-99.

21. Lorig K, Chastain RL, Ung E, Shoor S, Holman HR. Development and evaluation of a scale to measure perceived self-efficacy in people with arthritis. Arthritis and rheumatism. 1989;32(1):37-44.

22. O'Leary H, Smart KM, Moloney NA, Blake C, Doody CM. Pain sensitization associated with nonresponse after physiotherapy in people with knee osteoarthritis. Pain. 2018;159(9):1877-86.

23. Quicke JG, Foster NE, Croft PR, Ogollah RO, Holden MA. Change in physical activity level and clinical outcomes in older adults with knee pain: a secondary analysis from a randomised controlled trial. BMC musculoskeletal disorders. 2018;19(1):59.

24. Hay EM, Foster NE, Thomas E, Peat G, Phelan M, Yates HE, et al. Effectiveness of community physiotherapy and enhanced pharmacy review for knee pain in people aged over 55 presenting to primary care: pragmatic randomised trial. Bmj. 2006;333(7576):995.

25. Marks R. Knee osteoarthritis and exercise adherence: a review. Current aging science. 2012;5(1):72-83.

26. Marks R, Allegrante JP. Chronic osteoarthritis and adherence to exercise: a review of the literature. JAging PhysAct. 2005;13(4):434-60.

27. Nicolson PJA, Hinman RS, Wrigley TV, Stratford PW, Bennell KL. Effects of Covertly Measured Home Exercise Adherence on Patient Outcomes Among Older Adults With Chronic Knee Pain. The Journal of orthopaedic and sports physical therapy. 2019;49(7):548-56.

28. Moseng T, Dagfinrud H, Osteras N. Implementing international osteoarthritis guidelines in primary care: uptake and fidelity among health professionals and patients. Osteoarthritis and cartilage / OARS, Osteoarthritis Research Society. 2019.

29. Jack K, McLean SM, Moffett JK, Gardiner E. Barriers to treatment adherence in physiotherapy outpatient clinics: A systematic review. Manual Therapy. 2010;15(3):220-8.

30. Naggara O, Raymond J, Guilbert F, Altman DG. The Problem of Subgroup Analyses: An Example from a Trial on Ruptured Intracranial Aneurysms. American Journal of Neuroradiology. 2011;32(4):633-6.

31. Moseng T, Dagfinrud H, Smedslund G, Osteras N. The importance of dose in land-based supervised exercise for people with hip osteoarthritis. A systematic review and meta-analysis. Osteoarthritis and cartilage / OARS, Osteoarthritis Research Society. 2017;25(10):1563-76.

32. Moseng T, Dagfinrud H, Smedslund G, Osteras N. Corrigendum to 'The importance of dose in land-based supervised exercise for people with hip osteoarthritis. A systematic review and meta-analysis' [Osteoarthritis Cartilage 25 (2017) 15631576]. Osteoarthritis and cartilage / OARS, Osteoarthritis Research Society. 2018;26(5):707-9.

33. Bartholdy C, Juhl C, Christensen R, Lund H, Zhang W, Henriksen M. The role of muscle strengthening in exercise therapy for knee osteoarthritis: A systematic review and meta-regression analysis of randomized trials. Seminars in arthritis and rheumatism. 2017;47(1):9-21.

34. Willett M, Duda J, Fenton S, Gautrey C, Greig C, Rushton A. Effectiveness of behaviour change techniques in physiotherapy interventions to promote physical activity adherence in lower limb osteoarthritis patients: A systematic review. PloS one. 2019;14(7):e0219482.

35. Nicolson PJA, Bennell KL, Dobson FL, Van Ginckel A, Holden MA, Hinman RS. Interventions to increase adherence to therapeutic exercise in older adults with low back pain and/or hip/knee osteoarthritis: a systematic review and metaanalysis. British journal of sports medicine. 2017;51(10):791-9.

36. Hunter DJ, Nicolson PJA, Little CB, Robbins SR, Wang X, Bennell KL. Developing strategic priorities in osteoarthritis research: Proceedings and recommendations arising from the 2017 Australian Osteoarthritis Summit. BMC musculoskeletal disorders. 2019;20(1):74.

Page 12/15 
37. Bennell KL, Dobson F, Hinman RS. Exercise in osteoarthritis: moving from prescription to adherence. Best practice \& research Clinical rheumatology. 2014;28(1):93-117.

38. Tuakli-Wosornu YA, Selzer F, Losina E, Katz JN. Predictors of Exercise Adherence in Patients With Meniscal Tear and Osteoarthritis. Archives of physical medicine and rehabilitation. 2016;97(11):1945-52.

39. Hoeksma HL, van den Ende CH, Breedveld FC, Ronday HK, Dekker J. A comparison of the OARSI response criteria with patient's global assessment in patients with osteoarthritis of the hip treated with a non-pharmacological intervention. Osteoarthritis and cartilage / OARS, Osteoarthritis Research Society. 2006;14(1):77-81.

40. Sallis JF, Saelens BE. Assessment of physical activity by self-report: status, limitations, and future directions. Research quarterly for exercise and sport. 2000;71(2 Suppl):S1-14.

\section{Additional File Legends}

File name:

Additional file 1

Title of the data:

Figure A. The SAMBA model for integrated OA care

Description of the data:

Figure A illustrates the SAMBA model for integrated OA care

File name:

Additional file 2

Title of the data:

Modified CONSORT 2010 checklist of information to include when reporting a randomised trial with extensions for steppedwedge design

Description of the data:

CONSORT 2010 checklist of information to include when reporting a randomised trial with extensions for stepped-wedge design

\section{Figures}


20152016

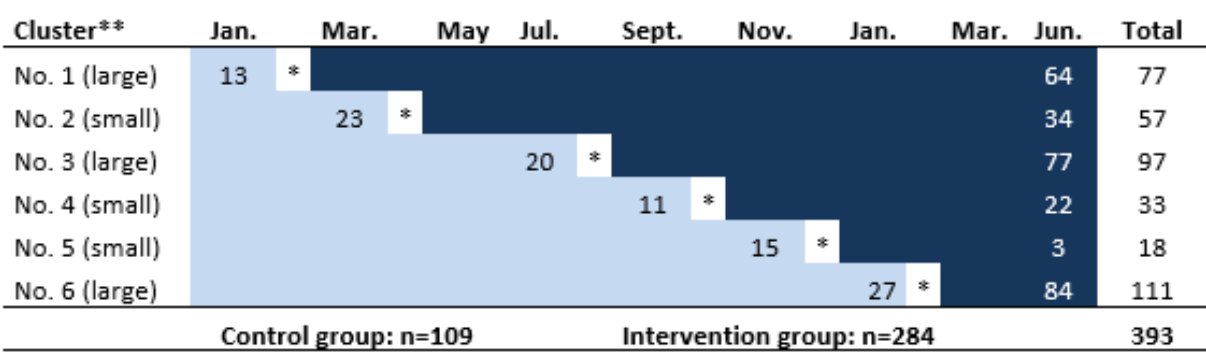

Figure XX. The stepped-wedge design, as applied in the SAMBA study, with number of included patients from the participating municipalities (clusters) in control and intervention phases. Light blue cells represent control periods; dark blue cells represent intervention periods. "Large municipalities (clusters) had $>20000$ inhabitants. *indicates the timing of the interactive workshops before switching to intervention phase.

\section{Figure 1}

The stepped-wedge cluster randomized design as applied for the SAMBA study

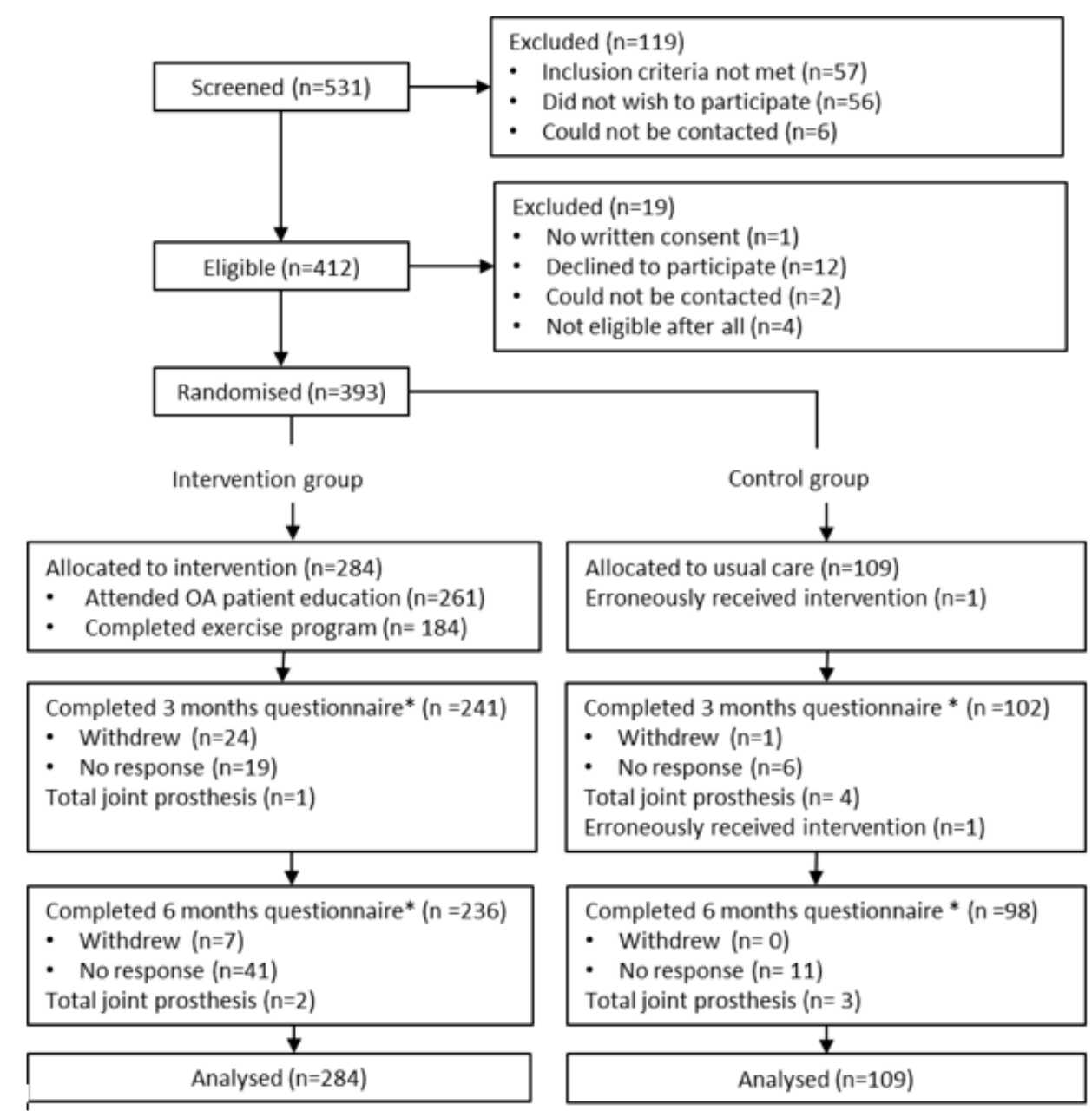

\section{Figure 2}

Flowchart of participants' progress through the phases of the trial. * Refers to the questions regarding pain, function and disease activity 

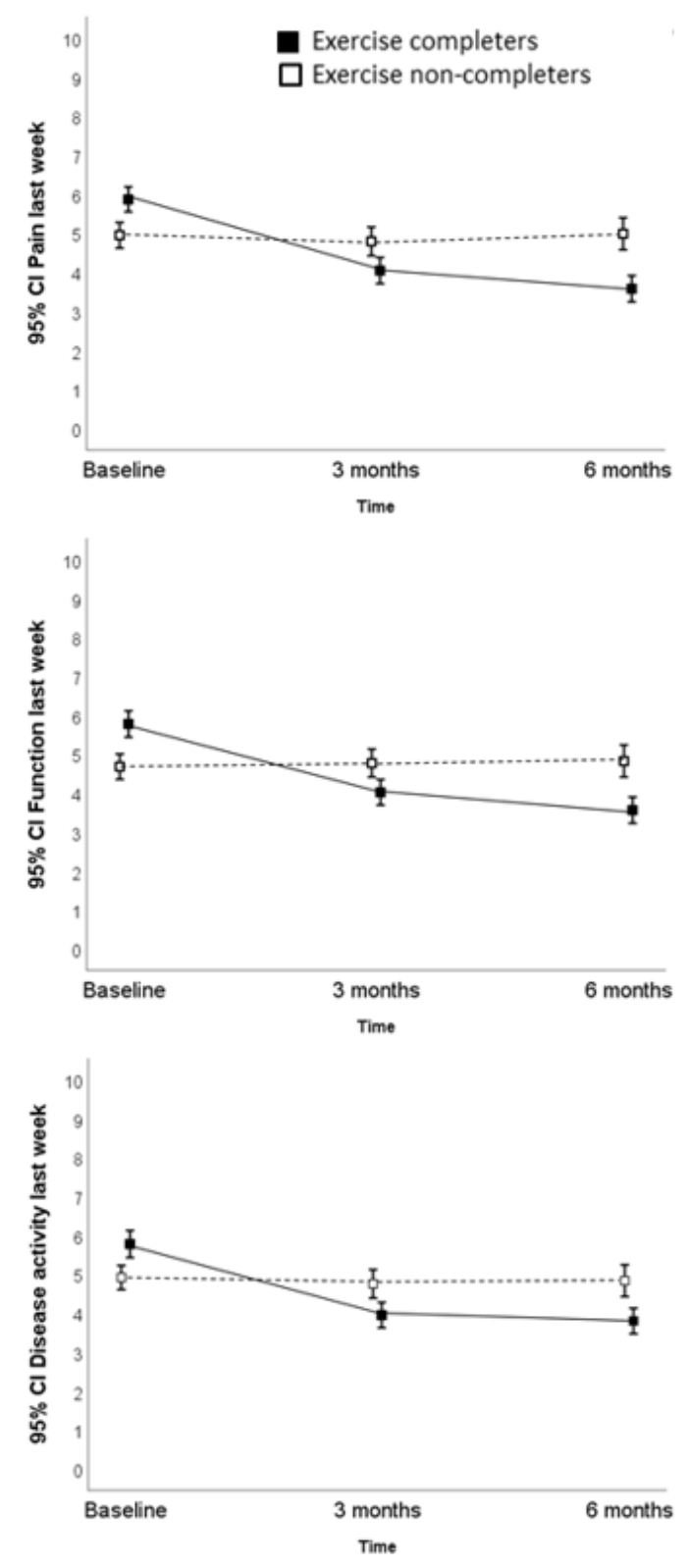

\section{Figure 3}

Difference in $\mathrm{OA}$ related pain, function and disease activity between exercise program completers (exercised $\geq 2$ times per week for $\geq 8$ weeks) and non-completers

\section{Supplementary Files}

This is a list of supplementary files associated with this preprint. Click to download.

- Additionalfile1.pdf

- Additionalfile2ConsortSWCRT.pdf

- CONSORT2010Checklistartikkel3.pdf 